\title{
Treatment options for severe hypertriglyceridemia (SHTG): the role of apheresis
}

\author{
Nils Ewald $\cdot$ Hans-Ulrich Kloer
}

Published online: 28 February 2012

(C) The Author(s) 2012. This article is published with open access at Springerlink.com

\begin{abstract}
Hypertriglyceridemia is associated with a number of severe diseases such as acute pancreatitis and coronary artery disease. In severe hypertriglyceridemia (SHTG, triglycerides $>1000 \mathrm{mg} / \mathrm{dl}$ ), rapid lowering of plasma triglycerides (TG) has to be achieved. Treatment regimes include nutritional intervention, the use of antihyperlipidemic drugs, and therapeutic apheresis. Apheretic treatment is indicated in medical emergencies such as hypertriglyceridemic pancreatitis.

Reviewing the current literature, plasmapheresis appears to be a safe and useful therapeutic tool in patients suffering from SHTG. Apheretic treatment is able to remove the causative agent for pancreatic inflammation. Data suggests that the use of apheresis should be performed as early as possible in order to achieve best results. The use of plasmapheresis, however, is limited due to the rather high costs and the limited availability of the procedure.
\end{abstract}

Keywords Apheresis - Hypertriglyceridemia ·

Pancreatitis $\cdot$ Plasma exchange

\section{Introduction}

Severe hypertriglyceridemia (SHTG) is well known to be associated with severe diseases such as acute pancreatitis and cardiovascular disease.

Concerning the role of triglycerides (TG) in promoting cardiovascular disease, there are still controversial discus-

PD Dr. N. Ewald $(\bowtie) \cdot$ Prof. Dr. H.-U. Kloer

Third Medical Department,

University Hospital Giessen and Marburg,

Giessen Site, Klinikstr. 33, 35392 Giessen, Germany

e-mail: nils.ewald@innere.med.uni-giessen.de sions more than 60 years after Moreton first postulated a relationship between them [1]. However, recent data on SHTG are likely to settle this debate by establishing a consistent strong relation of TG levels (especially nonfasting TG levels) with cardiovascular risk [2-5].

The role of SHTG in causing acute pancreatitis, however, is commonly accepted. According to the literature, SHTG is the most common cause for acute pancreatitis after gallstones and alcohol $[6,7]$. SHTG is reported to account for up to $10 \%$ of all acute pancreatitis episodes [8]. Some studies on gestational pancreatitis even report SHTG as the underlying etiology in more than half of all cases [9]. There is even some evidence that hypertriglyceridemic pancreatitis is associated with a higher severity and a higher complication rate $[10,11]$.

Since the association of SHTG and pancreatitis was first postulated by Speck [12] in 1865, the topic has attracted many research efforts. Several mechanisms for the disease have been proposed, including the hydrolysis of TGs forming free fatty acids inducing inflammation, chylomicrons inducing hyperviscosity leading to ischemia, and, finally, genetic predisposition $[13,14]$. In addition, cytokines seem to play a major role in acute pancreatitis including the systemic responses [15], yet the exact pathophysiology still remains unclear and is still controversially discussed.

It is generally believed that TG levels of $>1000 \mathrm{mg} /$ $\mathrm{dl}(11.3 \mathrm{mmol} / \mathrm{l})$ trigger acute pancreatitis and its serious complications. This threshold, however, is arbitrary and the level above which acute pancreatitis might occur is actually unknown. Therefore, rapid lowering of excessively elevated serum TG levels is a primary medical goal in preventing serious harm to the patient suffering from SHTG.

The general treatment regimen for SHTG includes dietary restrictions and lipid-lowering drug treatment such as the use of medium-chain triglycerides (MCT), fibrates, omega- 
3-fatty acids (omega-3-FA), and nicotinic acid. Yet, drugs of first choice, such as fibrates, do not offer fast onset of action, while immediately acting drugs like omega-3-FA and MCT may not be powerful enough to lower excessively elevated TG levels rapidly. Since patients with excessively elevated TG levels are in urgent need of a fast and effective lowering of their TG levels in order to prevent a severe pancreatitis episode, further measures must be taken. Immediate apheretic treatment might thus be an interesting option in order to rapidly lower excessively elevated TG levels and prevent or attenuate acute pancreatitis in these patients. Recently, the successful use of plasmapheresis for treating patients with SHTG has not only been confirmed in a number of studies, but has also been suggested by the American Society for Apheresis (ASFA) Committee on Clinical Applications.

\section{Causes of hypertriglyceridemia}

The causes of hypertriglyceridemia may be categorized into genetically based disorders (primary disorders) and secondary disorders due to other diseases. Till date, the only genetically well characterized kinds of SHTG are lipoprotein lipase (LPL) deficiency and apolipoprotein (Apo) C-II deficiency, which usually present in infancy as chylomicronemia syndromes causing SHTG at a very early childhood age. In adults, SHTG usually presents with very high fasting levels of chylomicrons, VLDL, and remnants [16]. This condition is probably of plurigenetic origin with a strong environmental and lifestyle impact on its manifestation. Occasionally, a patient with ApoE2/E2 homozygosis (dysbetalipoproteinemia, type III hyperlipoproteinemia) will develop SHTG.

There is a large number of secondary causes of SHTG. Among these, obesity, untreated diabetes mellitus, alcohol, pregnancy, and different drugs are probably the most common. Several of the secondary causes are associated with abnormalities of insulin responsiveness.

\section{Treatment of SHTG}

Nonpharmacological treatment options

Lifestyle changes and dietary modifications are essential features in the management of SHTG. Avoidance of alcohol, weight reduction, exercise, and control of (potential) concomitant endocrinopathy (e.g., diabetes mellitus and hypothyroidism) are imperative measures in the management of SHTG. Drugs with untoward effects must be avoided. Dietary advice by a nutritionist is obligatory.

A study of 32 patients with SHTG by Hauenschild et al. [17] highlights the positive effect of self-monitoring of lipid levels by patients at home. Patients were able to influence their diet individually to stabilize their TG levels and to avoid episodes of SHTG.

Pharmacological treatment options for SHTG

When tolerated by the patient, oral antihyperlipidemic drugs should be administered.

Table 1 displays an overview of the currently available drugs, their mechanisms of actions, their key benefits, and their limitations.

Diagnosis and treatment of a disease possibly underlying SHTG (e.g., diabetes mellitus, hypothyroidism, drug-induced-HTG) is imperative.

Insulin and/or heparin therapy

Insulin treatment is often considered helpful in lowering SHTG, because insulin activates LPL leading to an acceleration of chylomicron degradation. As SHTG often presents in poorly controlled diabetic patients, aggressive insulin treatment is especially helpful in those patients for the management of hyperglycemia as well as for activation of LPL. However, as many studies demonstrated, its use is not limited to diabetic patients [18-22]. Heparin, another agent often referred to, stimulates the release of endothelial LPL into the circulation $[21,22]$. Yet, heparin treatment in SHTG is subject to greater controversy due to the only transient rise in LPL followed by increased degradation and depletion of plasma stores resulting in LPL deficiency [23-25].

\section{Gene therapy}

Another treatment modality potentially useful for cases of SHTG with documented LPL deficiencies is described by Stroes et al. [26]. This treatment consists of local intramuscular application of a viral vector containing a LPL gene. This gene therapy enables the LPL-deficient patient to cope with postprandial chylomicronemia. Together with the other measures described above, LPL gene therapy may become a useful tool for achieving permanent control of SHTG in the future.

\section{Apheretic treatment of SHTG}

Apheresis for lowering TG levels was first reported in 1978 by Betteridge et al. [27] and plasmapheresis has since been a therapeutic tool for SHTG. Till date, several small studies [28-36] and case reports (overview by Iskandar and Olive [37]) on the use of apheresis in SHTG have been published. An overview of the currently available studies (more than ten patients) is given in Table 2. They all demonstrate 
Table 1 Pharmacological treatment options for SHGT

\begin{tabular}{|c|c|c|c|}
\hline $\begin{array}{l}\text { Treatment } \\
\text { modality }\end{array}$ & Mechanism of action & Comments & Limitations \\
\hline Fibrates & $\begin{array}{l}\text { Increase of LPL level, decrease in hepatic TG } \\
\text { synthesis by induction of hepatic FFA oxidation, } \\
\text { and stimulation of reverse cholesterol transport }\end{array}$ & Considered drugs of first choice & Slow onset of TG lowering \\
\hline $\begin{array}{l}\text { Nicotinic } \\
\text { acid }\end{array}$ & Reducing VLDL secretion via receptor & Reliable long-term effect on TG level & $\begin{array}{l}\text { Prominent side effects such as } \\
\text { facial flushing, slow onset of } \\
\text { TG lowering }\end{array}$ \\
\hline $\begin{array}{l}\text { HMG-CoA } \\
\text { reductase } \\
\text { inhibitors }\end{array}$ & Inhibition of cholesterol synthesis & $\begin{array}{l}\text { Only of use in combination with other } \\
\text { drugs such as fibrates in order to achieve } \\
\text { synergistic effects }\end{array}$ & $\begin{array}{l}\text { Higher risk of myositis or myo- } \\
\text { pathy, no drug of first choice }\end{array}$ \\
\hline Omega-3-FA & $\begin{array}{l}\text { Reduced hepatic TG synthesis, enhanced } \\
\text { peroxisomal } \beta \text {-oxidation, increased LPL activity } \\
\text { and adipose tissue LPL expression }\end{array}$ & $\begin{array}{l}\text { Potent drug with no side effects, immedia- } \\
\text { te onset of action }\end{array}$ & No limitations \\
\hline MCT & $\begin{array}{l}\text { No chylomicron formation, no chylomyicron } \\
\text { synthesis, induction of michondrial } \beta \text {-oxidation } \\
\text { of FA }\end{array}$ & Immediate onset of action on TG levels & No limitations \\
\hline Insulin & $\begin{array}{l}\text { Activation of LPL (acceleration of chylomicron } \\
\text { degradation) }\end{array}$ & $\begin{array}{l}\text { Useful especially in the treatment of } \\
\text { poorly controlled diabetic subjects with } \\
\text { HTG }\end{array}$ & Only of limited efficiency \\
\hline Heparin & Stimulation of release of endothelial LPL & Not recommended as a monotherapy & $\begin{array}{l}\text { Cave: increased LPL degra- } \\
\text { dation and depletion of LPL } \\
\text { plasma stores }\end{array}$ \\
\hline
\end{tabular}

Note carefully that conventional treatment of any comorbidity, e.g., pancreatitis is imperative as well as screening for secondary causes of HTG and treatment of the underlying disease

$L P L$ lipoprotein lipase; $T G$ triglycerides; $F A$ fatty acids; $F F A$ free fatty acid; $V L D L$ very low density lipoproteins; $H M G$ - $C O A$ hydroxymethylglutaryl-coenzyme-A; $M C T$ medium-chain triglycerides; $H T G$ hypertriglyceridemia

Table 2 Overview of the currently available studies (more than 10 patients) on the use of apheresis in SHTG

\begin{tabular}{llll} 
Reference & $\begin{array}{l}\text { Patients } \\
\text { included }\end{array}$ & $\begin{array}{l}\text { Plasma exchange } \\
\text { method }\end{array}$ & $\begin{array}{l}\text { Significant } \\
\text { reduction on } \\
\text { TG level }\end{array}$ \\
\hline $\begin{array}{l}\text { Stefanutti et al. [28] } \\
\text { Yeh et al. [30] }\end{array}$ & 17 & $\begin{array}{l}\text { Albumin } \\
\text { FFP and albumin, } \\
\text { double membrane } \\
\text { filtration }\end{array}$ & $\begin{array}{l}\text { By } 61 \% \\
\text { By } 66 \% \text { (first } \\
\text { setting) and by } \\
83 \% \text { (second } \\
\text { setting) }\end{array}$ \\
Yeh et al. [31] & 17 & FFP and albumin & $\begin{array}{l}\text { Significant } \\
\text { reduction } \\
\text { n.a. }\end{array}$ \\
Chen et al. [32] & 94 & FFP and albumin \\
Gubensek et al. [34] & 50 & Albumin & $\begin{array}{l}\text { Significant } \\
\text { reduction } \\
\text { By 62\% }\end{array}$ \\
Kyriakidis et al. [35] & 10 & FFP &
\end{tabular}

effectiveness of the apheretic treatment by showing a rapid decrease in TG levels over a short period of time.

The beneficial effect of plasmapheresis is believed to be due to a rapid decrease in TG levels, yet removal of excessive proteases from the plasma and replacement of consumed protease-inhibitors might play an additionally beneficial role.

A multicenter study by Stefanutti et al. [28] included 17 patients with SHTG who had not responded to conventional medical therapy (fat-free diet plus pharmaceutical inter- ventions). After treatment, the mean plasma TG and total cholesterol concentrations were significantly reduced from 1,929 and $510 \mathrm{mg} / \mathrm{dl}$ to 762 and $227 \mathrm{mg} / \mathrm{dl}$, respectively. The removal of TG-rich lipoproteins by therapeutic plasma exchange (TPE) prevented relapses of acute pancreatitis episodes. TPE was confirmed as a safe and reliable method.

According to the data of Lennertz et al. [29] and Yeh et al. [30, 31], a single session of plasmapheresis proofs capable of dramatically lowering TG levels by up to $70 \%$ producing clear clinical and laboratory improvement of acute pancreatitis.

As many studies suggest, the timing of the apheretic treatment might be crucial $[29,32,33]$. There are several reports showing that maximal reduction in morbidity and mortality can be achieved when apheresis is used as early as possible [38, 39]. Lennertz et al. [29] performed a retrospective analysis of five cases treated by TPE immediately after diagnosis. A TG reduction by $65-70 \%$ was observed. All patients were discharged in a good condition. Among the subjects was a pregnant patient with SHTG-induced pancreatitis, who gave birth to a healthy child later on.

A study by Kyriakidis et al. [35] included ten patients with pancreatitis due to SHTG, who underwent plasmapheresis within $48 \mathrm{~h}$ of diagnosis. They all showed a significant improvement in their general condition and a regression of pain, only one patient died in this study. 
Table 3 Suggested treatment regime for SHGT

\begin{tabular}{|c|c|}
\hline $\begin{array}{l}\text { Acute treatment in severe } \\
\text { HTG }(\mathrm{TG}>1000 \mathrm{mg} / \mathrm{dl})\end{array}$ & $\begin{array}{l}\text { Long-term treatment for the prevention } \\
\text { of severe HTG episodes (TG levels to } \\
\text { be reached } 300-500 \mathrm{mg} / \mathrm{dl} \text { ) }\end{array}$ \\
\hline $\begin{array}{l}\text { Apheresis until plasma } \\
\text { TG level }<1000 \mathrm{mg} / \mathrm{dl}\end{array}$ & Dietary measurements \\
\hline \multirow[t]{5}{*}{$\begin{array}{l}\text { MCT and omega-3-FA } \\
\text { in combination }\end{array}$} & $\begin{array}{l}<20 \text { g LC-FA/day, abstinence of } \\
\text { alcohol }\end{array}$ \\
\hline & $\begin{array}{l}\text { Adding omega-3-FA ( }>3 \mathrm{~g} \\
\mathrm{EPA}+\mathrm{DHA})\end{array}$ \\
\hline & Adding fibrates to omega-3-FA \\
\hline & $\begin{array}{l}\text { Adding nicotinic acid to fibrates, } \\
\text { omega-3-FA }\end{array}$ \\
\hline & $\begin{array}{l}\text { Considering recurrent episodes of } \\
\text { plasmapheresis }\end{array}$ \\
\hline
\end{tabular}

Note carefully that conventional treatment of any comorbidity, e.g., pancreatitis is imperative as well as screening for secondary causes of HTG and treatment of the underlying disease

$H T G$ hypertriglyceridemia; $T G$ triglycerdies; $F A$ fatty acids; $M C T$ medium-chain triglycerides; $L C-F A$ long-chain fatty acids; $E P A$ eicosapentaenoic acid; $D H A$ docosahexaenoic acid

Chen et al. [32] compared two groups of patients before and after the availability of apheresis in a larger retrospective study. No benefit concerning the rate of overall mortality and complications could be detected. However, as concluded by the authors, the timing of apheresis might exactly be the critical point in this study.

Technical details concerning apheretic treatment are also increasingly under investigation. Till date, there are two small studies comparing plasmapheresis with double membrane filtration in patients with SHTG [31, 40]. Both studies were able to show a significant reduction in TG levels. Plasma exchange therapy seemed slightly more efficient than double membrane filtration (removal rate 64.1 vs. $57.5 \%)[40]$.

\section{Conclusions}

Plasmapheresis appears to be a safe and useful therapeutic tool in patients suffering from SHTG. Apheretic treatment is able to remove the causative agent for continuing damage to the pancreas by rapidly lowering excessively elevated TG levels. Data suggests that the use of apheresis in patients with SHTG should be performed as early as possible in order to achieve best results.

Plasmapheresis, however, is a rather expensive treatment option and not available in all centers. This might therefore limit its use.

Apheretic treatment is indicated in medical emergencies such as hypertriglyceridemic pancreatitis if TG levels are excessively elevated ( $\mathrm{TG}>1000 \mathrm{mg} / \mathrm{dl}$ ). Apheretic treatment should be performed until TG levels have been lowered to $<500 \mathrm{mg} / \mathrm{dl}$. Following apheretic treatment, we recommend a 1-2 weeks of nutritional intervention with an MCT and omega-3-FA-rich diet according to the data presented by Hauenschild et al. [41]. A rigorous pharmacological treatment, dietary advice by a nutritionist and lifestyle changes are imperative. Suggestions for an efficient treatment regime of these patients are presented in Table 3.

Acknowledgments This article is part of a supplement sponsored by an unrestricted educational grant from B. Braun and Fresenius Medical Care.

Conflict of interest The authors declare that they have no conflict of interest.

Open Access This article is distributed under the terms of the Creative Commons Attribution License which permits any use, distribution, and reproduction in any medium, provided the original author(s) and the source are credited.

\section{References}

1. Moreton JR (1947) Atherosclerosis and alimentary hyperlipemia. Science 106:190-191

2. Sarwar N, Danesh J, Eiriksdottir G, Sigurdsson G, Wareham N, Bingham S, Boekholdt SM, Khaw KT, Gudnason V (2007) Triglycerides and the risk of coronary heart disease: 10158 incident cases among 262525 participants in 29 western prospective studies. Circulation 115:450-458

3. Bansal S, Buring JE, Rifai N, Mora S, Sacks FM, Ridker PM (2007) Fasting compared with nonfasting triglycerides and risk of cardiovascular events in women. JAMA 298:309-316

4. Tirosh A, Rudich A, Shochat T, Tekes-Manova D, Israeli E, Henkin Y, Kochba I, Shai I (2007) Changes in triglyceride levels and risk for coronary heart disease in young men. Ann Intern Med 147:377-385

5. Nordestgaard BG, Benn M, Schnohr P, Tybjaerg-Hansen A (2007) Nonfasting triglycerides and risk of myocardial infarction, ischemic heart disease, and death in men and women. JAMA 298:299-308

6. Fortson MR, Freedman SN, Webster PD III (1995) Clinical assessment of hyperlipidemic pancreatitis. Am J Gastroenterol 90:2134-2139

7. Toskes PP (1990) Hyperlipidemic pancreatitis. Gastroenterol Clin North Am 19:783-791

8. Anderson F, Thomson SR, Clarke DL, Buccimazza I (2009) Dyslipidaemic pancreatitis clinical assessment and analysis of disease severity and outcomes. Pancreatology 9:252-257

9. Chang CC, Hsieh YY, Tsai HD, Yang TC, Yeh LS, Hsu TY (1998) Acute pancreatitis in pregnancy. Zhonghua Yi Xue Za Zhi 61:85-92

10. Lloret Linares C, Pelletier AL, Czernichow S, Vergnaud AC, Bonnefont-Rousselot D, Levy P, Ruszniewski P, Bruckert E (2008) Acute pancreatitis in a cohort of 129 patients referred for severe hypertriglyceridemia. Pancreas 37:13-22

11. Deng LH, Xue P, Xia Q, Yang XN, Wan MH (2008) Effect of admission hypertriglyceidemia on the episodes of severe acute pancreatitis. World J Gastroenterol 14:4558-4561

12. Speck L (1865) A case of lipidemia. Arch Verin Wiss Heilkd $1: 232$

13. Tsuang W, Navaneethan U, Ruiz L, Palascak JB, Gelrud A (2009) Hypertriglyceridemic pancreatitis: presentation and management. Am J Gastroenterol 104:984-991 
14. Ewald N, Hardt PD, Kloer HU (2009) Severe hypertriglyceridemia and pancreatitis: presentation and management. Curr Opin Lipidol 20:497-504

15. Escobar J, Pereda J, Arduini A, Sandoval J, Sabater L, Aparisi L, López-Rodas G, Sastre J (2009) Cross-talk between oxidative stress and pro-inflammatory cytokines in acute pancreatitis: a key role for protein phosphatases. Curr Pharm Des 15:3027-3042

16. Yadav D, Pitchumoni CS (2003) Issues in hyperlipidemic pancreatitis. J Clin Gastroenterol 36:54-62

17. Hauenschild A, Ewald N, Schnell-Kretschmer H, Porsch-Oezcueruemez M, Kloer HU, Hardt PD (2008) Successful long-term treatment of severe hypertriglyceridemia by feedback control with lipid self-monitoring. Ann Nutr Metab 52:215-220

18. Tamez-Perez HE, Saenz-Gallegos R, Hernandez-Rodriguez K, Forsbach-Sánchez G, Gómez-de Ossio MD, Fernández-Garza N, Zapata-de la Garza E, Tamez-Peña AL (2006) Insulin therapy in patients with severe hypertriglyceridemia. Rev Med Inst Mex Seguro Soc 44:235-237

19. Jabbar MA, Zuhri-Yag MI, Larrea J (1998) Insulin therapy for a nondiabetic patient with severe hypertriglyceridemia. J Am Coll Nutr 17:458-461

20. Mikhail N, Trivedi K, Page C, Wali S, Cope D (2005) Treatment of severe hypertriglyceridemia in nondiabetic patients with insulin. Am J Emerg Med 23:415-417

21. Jain P, Rai RR, Udawat H, Nijhawan S, Mathur A (2007) Insulin and heparin in treatment of hyper- triglyceridemia-induced pancreatitis. World J Gastroenterol 13:2642-2643

22. Alagözlü H, Cindoruk M, Karakan T, Unal S (2006) Heparin and insulin in the treatment of hypertriglyceridemia-induced severe acute pancreatitis. Dig Dis Sci 51:931-933

23. Näsström B, Stegmayr B, Gupta J, Olivecrona G, Olivecrona T (2005) A single bolus of a low molecular weight heparin to patients on haemodialysis depletes lipoprotein lipase stores and retards triglyceride clearing. Nephrol Dial Transplant 20:1172-1179

24. Weintraub M, Rassin T, Eisenberg S, Ringel Y, Grosskopf I, Iaina A, Charach G, Liron M, Rubinstein A (1994) Continuous intravenous heparin administration in humans causes a decrease in serum lipolytic activity and accumulation of chylomicrons in circulation. J Lipid Res 35:29-38

25. Näsström B, Olivecrona G, Olivecrona T, Stegmayr BG (2001) Lipoprotein lipase during continuous heparin infusion: tissue stores become partially depleted. J Lab Clin Med 138:206-213

26. Stroes ES, Nierman MC, Meulenberg JJ, Franssen R, Twisk J, Henny CP, Maas MM, Zwinderman AH, Ross C, Aronica E, High KA, Levi MM, Hayden MR, Kastelein JJ, Kuivenhoven JA (2008) Intramuscular administration of AAV1-lipoprotein lipase S447X lowers triglycerides in lipoprotein lipase-deficient patients. Arterioscler Thromb Vasc Biol 28:2303-2304

27. Betteridge DJ, Bakowski M, Taylor KG, Reckless JP, de Silva SR, Galton DJ (1978) Treatment of severe diabetic hypertriglyceridemia by plasma exchange. Lancet 1(8078):1368
28. Stefanutti C, Di Giacomo S, Vivenzio A, Labbadia G, Mazza F, D’Alessandri G, Russi G, De Silvestro G, Marson P (2009) Therapeutic plasma exchange in patients with severe hypertriglyceridemia: a multicenter study. Artif Organs 33(12):1096-1102

29. Lennertz A, Parhofer KG, Samtleben W, Bosch T (1999) Therapeutic plasma exchange in patients with chylomicronemia syndrome complicated by acute pancreatitis. Ther Apher 3:227-233

30. Yeh JH, Chen JH, Chiu HC (2003) Plasmapheresis for hyperlipidemic pancreatitis. J Clin Apher 18(4):181-185

31. Yeh JH, Lee MF, Chiu HC (2003) Plasmapheresis for severe lipemia: comparison of serum-lipid clearance rates for the plasma-exchange and double-filtration variants. J Clin Apher 18(1):32-36

32. Chen JH, Yeh JH, Lai HW, Liao CS (2004) Therapeutic plasma exchange in patients with hyperlipidemic pancreatitis. World $\mathrm{J}$ Gastroenterol 10(15):2272-2274

33. Kyriakidis AV, Karydakis P, Neofytou N, Pyrgioti M, Vasilakakis D, Digenis P, Antsaklis G (2005) Plasmapheresis in the management of acute severe hyperlipidemic pancreatitis: report of 5 cases. Pancreatology 5:201-204

34. Gubensek J, Buturović-Ponikvar J, Marn-Pernat A, Kovac J, Knap B, Premru V, Ponikvar R (2009) Treatment of hyperlipidemic acute pancreatitis with plasma exchange: a single-center experience. Ther Apher Dial 13(4):314-317

35. Kyriakidis AV, Raitsiou B, Sakagianni A, Harisopoulou V, Pyrgioti M, Panagopoulou A, Vasilakis N, Lambropoulos S (2006) Management of acute severe hyperlipidemic pancreatitis. Digestion 73:259-264

36. Kadikoylu G, Yavasoglu I, Bolaman Z (2006) Plasma exchange in severe hypertriglyceridemia a clinical study. Transfus Apher Sci 34:253-257

37. Iskandar SB, Olive KE (2004) Plasmapheresis as an adjuvant therapy for hypertriglyceridemia-induced pancreatitis. Am J Med Sci 328:290-294

38. Furuya T, Komatsu M, Takahashi K, Hashimoto N, Hashizume T, Wajima N, Kubota M, Itoh S, Soeno T, Suzuki K, Enzan K, Matsuo S (2002) Plasma exchange for hypertriglyceridemic acute necrotizing pancreatitis: report of two cases. Ther Apher $6: 454-458$

39. Ohmoto K, Neishi Y, Miyake I, Yamamoto S (1999) Severe acute pancreatitis associated with hyperlipidemia: report of two cases and review of the literature in Japan. Hepatogastroenterology 46(29):2986-2990

40. Giannini G, Valbonesi M, Morelli F, Carlier P, De Luigi MC, Dejana AM, Ruzzenenti MR (2005) Hypertriglyceridemia: apheretic treatment. Int J Artif Organs 28(10):1018-1024

41. Hauenschild A, Bretzel RG, Schnell-Kretschmer H, Kloer HU, Hardt PD, Ewald N (2010) Successful treatment of severe hypertriglyceridemia with a formula diet rich in omega-3 fatty acids and medium-chain triglycerides. Ann Nutr Metab 56(3):170-175 